Pacific Journal of Mathematics

ON DENSITIES OF SETS OF LATTICE POINTS 


\title{
ON DENSITIES OF SETS OF LATTICE POINTS
}

\author{
BetTy KVARDA
}

1. Introduction. Let $A$ be a set of positive integers, and for any positive integer $x$ denote by $A(x)$ the number of integers of $A$ which are not greater than $x$. Then the Schnirelmann density of $A$ is defined [4] to be the quantity

$$
\alpha=\underset{x}{\operatorname{glb}} \frac{A(x)}{x} .
$$

For any $k$ sets $A_{1}, \cdots, A_{k}$ of positive integers, $k \geqq 2$, let the sum set $A_{1}+\cdots+A_{k}$ be the set of all nonzero sums $a_{1}+\cdots+a_{k}$ for which each $a_{i}, i=1, \cdots, k$, is either contained in $A_{i}$ or is 0 . Let $k A$ be the set $A+\cdots+A$ with $k$ summands.

Schnirelmann [4] and Landau [2] have shown that if $A$ and $B$ are two sets of positive integers with $C=A+B$, and if $\alpha, \beta, \gamma$ are the Schnirelmann densities of $A, B, C$, respectively, then $\gamma \geqq \alpha+\beta-\alpha \beta$, and if $\alpha+\beta \geqq 1$ then $\gamma=1$. They have also shown that if $A$ is a set of positive integers whose Schnirelmann density is positive then $A$ is a basic sequence for the set of positive integers, or, in other words, there exists a positive integer $k$ such that every positive integer can be written as the sum of at most $k$ elements of $A$.

We will show that by using extensions of the methods employed by Schnirelmann and Landau the above results can be generalized to certain sets of vectors in a discrete lattice (for definition and discussion see [3, pp. 28-31] or [5, pp. 141-145]). Without loss of generality it may be assumed that the components of the vectors in such a lattice are rational integers. The usual identification of algebraic integers with lattice points then gives an immediate extension of these results to algebraic integers.

2. Notation and definitions. Let $Q_{n}$ be the set of all $n$-dimensional lattice points $\left(x_{1}, \cdots, x_{n}\right), n \geqq 1$, for which each $x_{i}, i=1, \cdots, n$, is a nonnegative integer and at least one $x_{i}$ is positive. Define the sum of subsets of $Q_{n}$ in the same manner as was done for sets of positive integers, and for any subsets $A$ and $B$ of $Q_{n}$ let $A-B$ denote the set of all elements of $A$ which are not in $B$. If $A$ and $S$ are subsets of $Q_{n}$ and $S$ is finite let $A(S)$ be the number of elements in $A \cap S$.

Definition 1. A finite nonempty subset $R$ of $Q_{n}$ will be called a

Received August 10, 1962, and in revised form February 27, 1963. The author is indebted to the referee for a suggestion which has greatly simplified the proof of Theorem 2 . 
fundamental subset of $Q_{n}$ or, briefly, a fundamental set, if whenever an element $\left(r_{1}, \cdots, r_{n}\right)$ is in $R$ then all elements $\left(x_{1}, \cdots, x_{n}\right)$ of $Q_{n}$ such that $x_{i} \leqq r_{i}, i=1, \cdots, n$, are also in $R$.

Definition 2. Let $A$ be any subset of $Q_{n}$. The density of $A$ is defined to be the quantity

$$
\alpha=\operatorname{glb} \frac{A(R)}{Q_{n}(R)}
$$

taken over all fundamental sets $R$.

3. Extension of the Landau-Schnirelmann results. Throughout this section we let $A$ and $B$ be subsets of $Q_{n}$ with $C=A+B$, and let $\alpha, \beta, \gamma$ be the densities of $A, B, C$, respectively.

\section{THEOREM 1. If $\alpha+\beta \geqq 1$ then $\gamma=1$.}

Proof. Assume $\gamma<1$. Then there exists a fundamental set $R$ for which $C(R)<Q_{n}(R)$, which in turn implies that there exists an element $\left(x_{1}^{0}, \cdots, x_{n}^{0}\right)$ in $Q_{n}-C$. Let $R_{0}$ be the set of all elements $\left(x_{1}, \cdots, x_{n}\right)$ in $Q_{n}$ for which $x_{i} \leqq x_{i}^{0}, i=1, \cdots, n$. Then for any $\left(x_{1}, \cdots, x_{n}\right)$ in $R_{0}$ either $\left(x_{1}, \cdots, x_{n}\right)$ is in $A$, or $\left(x_{1}, \cdots, x_{n}\right)=\left(x_{1}^{0}, \cdots, x_{n}^{0}\right)-\left(b_{1}, \cdots, b_{n}\right)$ for some $\left(b_{1}, \cdots, b_{n}\right)$ in $B \cap R_{0}$, or neither, but not both. In particular, $\left(x_{1}^{0}, \cdots, x_{n}^{0}\right)$ is neither. Hence,

$$
A\left(R_{0}\right)+B\left(R_{0}\right) \leqq Q_{n}\left(R_{0}\right)-1,
$$

and

$$
\alpha+\beta \leqq \frac{A\left(R_{0}\right)+B\left(R_{0}\right)}{Q_{n}\left(R_{0}\right)}<1
$$

which is a contradiction. Therefore $\gamma=1$.

THEOREM 2. $\gamma \geqq \alpha+\beta-\alpha \beta$.

Proof. Let $\omega_{i}, 1 \leqq i \leqq n$, be that vector in $Q_{n}$ for which the $i$ th component is 1 and the other components, if any, are 0 . If any one of the vectors $\omega_{1}, \cdots, \omega_{n}$ is missing from $A$ then $\alpha=0$ and the theorem is trivial. Hence we assume all the vectors $\omega_{1}, \cdots, \omega_{n}$ are in $A$. We must show

$$
\frac{C(R)}{Q_{n}(R)} \geqq \alpha+\beta-\alpha \beta
$$

for all fundamental sets $R$. If $C(R)=Q_{n}(R)$ then (1) holds, since 
$(1-\alpha)(1-\beta) \geqq 0$ implies $1 \geqq \alpha+\beta-\alpha \beta$. Therefore we assume $C(R)<Q_{n}(R)$ and, consequently, $A(R)<Q_{n}(R)$.

Let $H=R-A$. We will show that there exist vectors $a^{(1)}, \cdots, a^{(s)}$ in $A$ and sets $L_{1}, \cdots, L_{s}$ with the following properties.

(i) $L_{i} \subseteq H$ and $L_{i}$ is not empty, $i=1, \cdots, s$.

(ii) The sets $L_{i}^{\prime}=\left\{x-a^{(i)} \mid x \in L_{i}\right\}$ are fundamental sets.

(iii) $L_{i} \cap L_{j}=\phi$ for $i \neq j$.

(iv) $H=L_{1} \cup \cdots \cup L_{s}$.

Let the elements of $R$ be ordered so that $\left(x_{1}, \cdots, x_{n}\right)>\left(x_{1}^{\prime}, \cdots, x_{n}^{\prime}\right)$ if $x_{1}>x_{1}^{\prime}$ or if $x_{1}=x_{1}^{\prime}, \cdots, x_{p}=x_{p}^{\prime}, x_{p+1}>x_{p+1}^{\prime}$. For every $h=\left(h_{1}, \cdots, h_{n}\right)$ in $H$, let $A_{h}$ be the set of all $\left(a_{1}, \cdots, a_{n}\right)$ in $A$ such that each $a_{i} \leqq h_{i}$. The sets $A_{h}$ are not empty since $\omega_{i} \in A$ for $i=1, \cdots, n$. The $A_{h}$ are finite sets, hence they contain (in our ordering) a largest vector. Let $a^{(1)}, \cdots, a^{(s)}$ be all the distinct vectors that are largest vectors in any $A_{h}$. Let $L_{i}$ be the set of all vectors $x$ in $H$ such that $a^{(i)}$ is the largest vector in $A_{x}$.

That (i), (iii), and (iv) are satisfied follows immediately from this definition of the $L_{i}$. To prove (ii) consider a vector $y=\left(y_{1}, \cdots, y_{n}\right)$ such that

$$
x_{j} \geqq y_{j} \geqq \alpha_{j}^{(i)},
$$

where $x=\left(x_{1}, \cdots, x_{n}\right)$ is in $L_{i}$ and $y \neq a^{(i)}$. Suppose $y \in L_{k}, k \neq i$. Then

$$
x_{j} \geqq y_{j} \geqq a_{j}^{(k)}
$$

and $a^{(k)} \geqq a^{(i)}$. But (2) and (3) and $x \in L_{i}$ imply $a^{(k)} \leqq a^{(i)}$, hence $a^{(k)}=$ $a^{(i)}$. Similarly, $y \in A$ implies $y=a^{(i)}$. This proves (ii).

If $b \in B \cap L_{i}^{\prime}$ then $a^{(i)}+b$ is in $C \cap L_{i}$, hence in $C-A$. Therefore,

$$
\begin{aligned}
C(R) & \geqq A(R)+B\left(L_{1}^{\prime}\right)+\cdots+B\left(L_{s}^{\prime}\right) \\
& \geqq A(R)+\beta\left[Q_{n}\left(L_{1}^{\prime}\right)+\cdots+Q_{n}\left(L_{s}^{\prime}\right)\right] \\
& =A(R)+\beta\left[Q_{n}\left(L_{1}\right)+\cdots+Q_{n}\left(L_{s}\right)\right] \\
& =A(R)+\beta\left[Q_{n}(H)\right] \\
& =A(R)+\beta\left[Q_{n}(R)-A(R)\right] \\
& =(1-\beta) A(R)+\beta\left[Q_{n}(R)\right] \\
& \geqq(1-\beta) \alpha\left[Q_{n}(R)\right]+\beta\left[Q_{n}(R)\right],
\end{aligned}
$$

and

$$
\frac{C(R)}{Q_{n}(R)} \geqq \alpha+\beta-\alpha \beta,
$$

which completes the proof. 
CoROllary 1. Let $A_{1}, \cdots, A_{k}$ be any $k$ subsets of $Q_{n}, k \geqq 2$, let $\alpha_{i}$ be the density of $A_{i}$ for $i=1, \cdots, k$, and let $d\left(A_{1}+\cdots+A_{k}\right)$ be the density of $A_{1}+\cdots+A_{k}$. Then

$$
1-d\left(A_{1}+\cdots+A_{k}\right) \leqq\left(1-\alpha_{1}\right) \cdots\left(1-\alpha_{k}\right) .
$$

Proof. If $k=2$ then Theorem 2 implies that $1-d\left(A_{1}+A_{2}\right) \leqq$ $1-\alpha_{1}-\alpha_{2}+\alpha_{1} \alpha_{2}=\left(1-\alpha_{1}\right)\left(1-\alpha_{2}\right)$. Hence assume $1-d\left(A_{1}+\cdots+A_{k-1}\right) \leqq$ $\left(1-\alpha_{1}\right) \cdots\left(1-\alpha_{k-1}\right)$. Then

$$
\begin{aligned}
1-d\left(A_{1}+\cdots+A_{k-1}+A_{k}\right) & \leqq\left[1-d\left(A_{1}+\cdots+A_{k-1}\right)\right]\left(1-\alpha_{k}\right) \\
& \leqq\left(1-\alpha_{1}\right) \cdots\left(1-\alpha_{k-1}\right)\left(1-\alpha_{k}\right) .
\end{aligned}
$$

Corollary 2. If $A$ is any subset of $Q_{n}$ with density $\alpha>0$ then there exists an integer $k>0$ such that $k A=Q_{n}$.

Proof. There exists an integer $m>0$ such that $(1-\alpha)^{m} \leqq 1 / 2$. Let $d(m A)$ be the density of $m A$. Then Corollary 1 implies that 1 $d(m A) \leqq(1-\alpha)^{m} \leqq 1 / 2$, or $d(m A) \geqq 1 / 2$. From Theorem $1, d(m A)+$ $d(m A) \geqq 1$ implies $d(2 m A)=1$, or $2 m A=Q_{n}$.

4. Remark. We may identify $Q_{2}$ with the set of nonzero Gaussian integers $x+y i$ for which $x$ and $y$ are both nonnegative rational integers. Luther Cheo [1] defined density for subsets of this $Q_{2}$ as follows, using our notation.

Definition 3. Let $x_{0}+y_{0} i$ be any element of $Q_{2}$ and $S$ the set of all $x+y i$ in $Q_{2}$ such that $x \leqq x_{0}$ and $y \leqq y_{0}$. Then for any subset $A$ of $Q_{2}$ the density of $A$ is the quantity

$$
\alpha_{c}=\underset{S}{\operatorname{glb}} \frac{A(S)}{Q_{2}(S)} .
$$

Cheo proved Theorem 1 for his density and also a theorem which implies that if $j i$ is in $A$ for all $j=1,2, \cdots$, and if $\alpha_{c}, \beta_{c}, \gamma_{c}$ are the Cheo densities of $A, B, C=A+B$, respectively, then

$$
\gamma_{c} \geqq \alpha_{c}+\beta_{c}-\alpha_{c} \beta_{c} .
$$

We cannot remove the requirement that all $j i$ be in $A$ by means of an argument like that used to establish Theorem 2 since it would be necessary to partition $H$ in such a way that the sets $L_{j}^{\prime}$ are of the type $S$ used in defining the Cheo density, and this is not always possible. Consider, for example, the set $R=\left\{x+y i: x+y i\right.$ is in $\left.Q_{2}, x \leqq 4, y \leqq 3\right\}$, and let $A \cap R=\{1, i, 3+3 i\}$. Then $H=R-A$ cannot be so partitioned, as the reader can easily verify. 


\section{REFERENCES}

1. L. P. Cheo, On the density of sets of Gaussian integers, Amer. Math. Monthly 58 (1951), 618-620.

2. E. Landau, Über einige neuere Fortschritte der additiven Zahlentheorie, Cambridge Univ. Press, London, 1937.

3. H. B. Mann, Introduction to algebraic number theory, The Ohio State Univ. Press, Columbus, 1955.

4. L. Schnirelmann, Über additive Eigenschaften von Zahlen, Math. Ann., 107 (1933), 649-690.

5. H. Weyl, Algebraic theory of numbers, Princeton Univ. Press, Princeton, 1940.

San Diego State College 



\title{
PACIFIC JOURNAL OF MATHEMATICS
}

\author{
EDITORS
}

\author{
Ralph S. Phillips \\ Stanford University \\ Stanford, California \\ M. G. Arsove \\ University of Washington \\ Seattle 5 , Washington
}

\author{
J. DugunduI \\ University of Southern California \\ Los Angeles 7, California
}

Lowell J. Paige

University of California

Los Angeles 24, California

\section{ASSOCIATE EDITORS}

E. F. BECKENBACH

T. M. CHERRY
D. DERRY
M. OHTSUKA

H. L. ROYDEN

E. SPANIER
E. G. STRAUS

F. WOLF

\section{SUPPORTING INSTITUTIONS}

UNIVERSITY OF BRITISH COLUMBIA CALIFORNIA INSTITUTE OF TECHNOLOGY UNIVERSITY OF CALIFORNIA MONTANA STATE UNIVERSITY UNIVERSITY OF NEVADA NEW MEXICO STATE UNIVERSITY OREGON STATE UNIVERSITY UNIVERSITY OF OREGON OSAKA UNIVERSITY UNIVERSITY OF SOUTHERN CALIFORNIA
STANFORD UNIVERSITY

UNIVERSITY OF TOKYO

UNIVERSITY OF UTAH

WASHINGTON STATE UNIVERSITY

UNIVERSITY OF WASHINGTON

AMERICAN MATHEMATICAL SOCIETY CALIFORNIA RESEARCH CORPORATION SPACE TECHNOLOGY LABORATORIES NAVAL ORDNANCE TEST STATION

Mathematical papers intended for publication in the Pacific Journal of Mathematics should be typewritten (double spaced), and the author should keep a complete copy. Manuscripts may be sent to any one of the four editors. All other communications to the editors should be addressed to the managing editor, L. J. Paige at the University of California, Los Angeles 24, California.

50 reprints per author of each article are furnished free of charge; additional copies may be obtained at cost in multiples of 50 .

The Pacific Journal of Mathematics is published quarterly, in March, June, September, and December. Effective with Volume 13 the price per volume (4 numbers) is $\$ 18.00$; single issues, $\$ 5.00$. Special price for current issues to individual faculty members of supporting institutions and to individual members of the American Mathematical Society: $\$ 8.00$ per volume; single issues \$2.50. Back numbers are available.

Subscriptions, orders for back numbers, and changes of address should be sent to Pacific Journal of Mathematics, 103 Highland Boulevard, Berkeley 8, California.

Printed at Kokusai Bunken Insatsusha (International Academic Printing Co., Ltd.), No. 6, 2-chome, Fujimi-cho, Chiyoda-ku, Tokyo, Japan.

PUBLISHED BY PACIFIC JOURNAL OF MATHEMATICS, A NON-PROFIT CORPORATION

The Supporting Institutions listed above contribute to the cost of publication of this Journal, but they are not owners or publishers and have no responsibility for its content or policies. 


\section{Pacific Journal of Mathematics}

\section{Vol. 13, No. 2 \\ April, 1963}

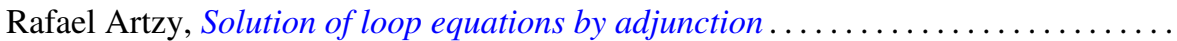

Earl Robert Berkson, A characterization of scalar type operators on reflexive

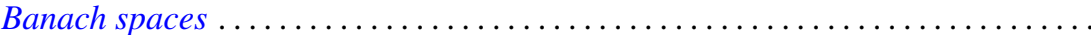

Mario Borelli, Divisorial varieties

365

Raj Chandra Bose, Strongly regular graphs, partial geometries and partially

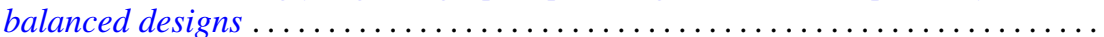

389

R. H. Bruck, Finite nets. II. Uniqueness and imbedding ............... 421

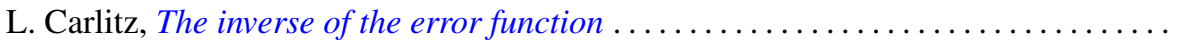

Robert Wayne Carroll, Some degenerate Cauchy problems with operator

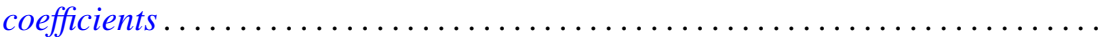

Michael P. Drazin and Emilie Virginia Haynsworth, A theorem on matrices of 0 's

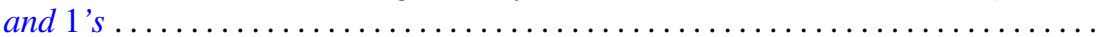

Lawrence Carl Eggan and Eugene A. Maier, On complex approximation .......... James Michael Gardner Fell, Weak containment and Kronecker products of group

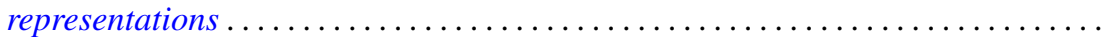

Paul Chase Fife, Schauder estimates under incomplete Hölder continuity

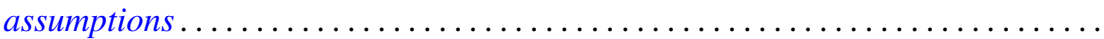

Shaul Foguel, Powers of a contraction in Hilbert space ...................

Neal Eugene Foland, The structure of the orbits and their limit sets in continuous

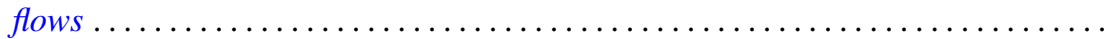

Frank John Forelli, Jr., Analytic measures . . . . . . . . . . . . . . . . . . . . . 563

Robert William Gilmer, Jr., On a classical theorem of Noether in ideal theory ....... P. R. Halmos and Jack E. McLaughlin, Partial isometries .

Albert Emerson Hurd, Maximum modulus algebras and local approximation in

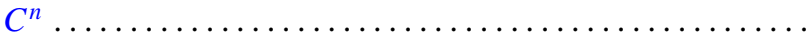

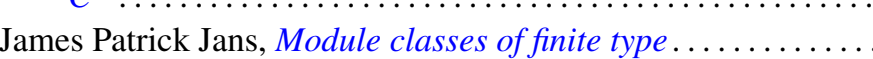

Betty Kvarda, On densities of sets of lattice points ...

H. Larcher, A geometric characterization for a class of discontinuous groups of linear fractional transformations .

John W. Moon and Leo Moser, Simple paths on polyhedra .

T. S. Motzkin and Ernst Gabor Straus, Representation of a point of a set as sum of

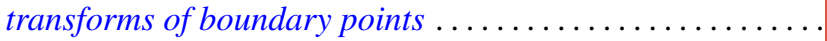

Rajakularaman Ponnuswami Pakshirajan, An analogue of Kolmogorov's three-series theorem for abstract random variables ...............

Robert Ralph Phelps, Čebyšev subspaces of finite codimension in $C(X)$...

James Dolan Reid, On subgroups of an Abelian group maximal disjoint from a given subgroup ...

William T. Reid, Riccati matrix differential equations and non-oscillation criteria for associated linear differential systems .................

Georg Johann Rieger, Some theorems on prime ideals in algebraic number fields ...

Gene Fuerst Rose and Joseph Silbert Ullian, Approximations of functions on the

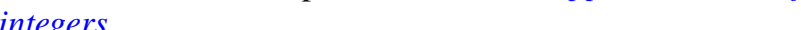

F. J. Sansone, Combinatorial functions and regressive isols . . . . . . . . . . 703

Leo Sario, On locally meromorphic functions with single-valued moduli . . . . . . . 709

Takayuki Tamura, Semigroups and their subsemigroup lattices.

Pui-kei Wong, Existence and asymptotic behavior of proper solutions of a class of second-order nonlinear differential equations . . ........... 